\title{
Multifocal photodynamic therapy for diffuse choroidal hemangioma
}

This article was published in the following Dove Press journal:

Clinical Ophthalmology

6 September 2012

Number of times this article has been viewed

\author{
Marcus Ang \\ Shu-Yen Lee \\ Singapore Eye Research Institute, \\ Singapore National Eye \\ Centre, Singapore
}

Background: A choroidal hemangioma is an uncommon benign vascular tumor of the choroid that can be either circumscribed or diffuse. In our experience, diffuse choroidal hemangiomas in Asian patients often require multiple photodynamic therapy (PDT) treatment sessions.

Methods: We here provide a case report of a 7-year-old boy with Sturge-Weber syndrome who presented with diffuse choroidal hemangioma in the left eye. Five sessions of PDT treatment were required over a period of 1 year and a final optical coherence tomogram 3 months later revealed resolution of subretinal fluid and the choroidal hemangioma.

Results: Final visual acuity was 20/100 in the left eye with resolution of subretinal fluid. This case report illustrates that a single application of PDT using standard published parameters was insufficient to achieve the destruction of the enlarged vessels. This experience is similar to previous Chinese reports on circumscribed choroidal hemangiomas. The decision for repeat treatment was based on subretinal fluid recurrence, rather than complete tumor regression.

Conclusion: Our case report supports previous suggestions that larger dilated vessels in the vascular network of a choroidal hemangioma might affect the efficacy and selectivity of PDT in treating the eyes of Asian patients - which may explain the need for multiple treatments.

Keywords: choroidal hemangioma, Sturge-Weber syndrome, optical coherence tomography

\section{Introduction}

Choroidal hemangioma is an uncommon benign vascular tumor of the choroid that can be either circumscribed or diffuse. ${ }^{1}$ Diffuse choroidal hemangiomas, usually associated with Sturge-Weber syndrome (SWS), are more likely to develop secondary retinal detachment. ${ }^{2}$

Diffuse choroidal hemangiomas have been treated using many modalities including radiotherapy, antivascular endothelial growth factor, and photodynamic therapy (PDT). ${ }^{2}$ Theoretically, PDT has ideal properties for such treatment as it offers sitespecific tumor destruction while sparing the overlying retina and retinal vasculature. ${ }^{3}$ To date, there have been only six case reports of successful single PDT treatment for diffuse choroidal hemangiomas. ${ }^{2}$ We present a case report to illustrate a case of diffuse choroidal hemangioma that was refractory to a single treatment.

\section{Case report}

A 7-year-old boy with SWS presented with blurring of vision in the left eye (OS) with increasing hypermetropia $(8.0 \mathrm{D}$ to $11.0 \mathrm{D})$ over a period of 6 months. At presentation, his best-corrected visual acuity (BCVA) was 20/20 right eye (OD) and 20/150 OS. Intraocular pressures were normal without evidence of iris neovascularization. Fundus examination 
of the left eye revealed a diffuse, orange choroidal tumor with overlying exudative retinal detachment (RD). B-scan ultrasound confirmed the presence of a diffuse choroidal hemangioma with thickening of the choroid and associated RD (Figure 1).

The patient underwent PDT with parameters typically used to treat choroidal neovascularization. Verteporfin was infused at a concentration of $6 \mathrm{mg} / \mathrm{m}^{2}$, and an 83 -second treatment was conducted with a $689 \mathrm{~nm}$ VISULAS 690s Photodynamic Therapy Laser System (Carl Zeiss Meditec, Inc., AG, Jena, Germany) that was delivered at $50 \mathrm{~J} / \mathrm{cm}^{2}$ with an intensity of $600 \mathrm{~mW} / \mathrm{cm}^{2}$. Five partially overlapping, maximally large spots $(5200 \mu \mathrm{m})$ were applied to the diffuse choroidal hemangioma. Optical coherence tomography was used to monitor treatment response (Figure 1A and Figure 2). However, because of persistent choroidal thickening and subretinal fluid, additional sessions of PDT, as described, were applied 2, 3, and 4 months post-presentation (a total of four sessions), with persistent subretinal fluid at ocular coherence tomography (OCT) thicknesses of $557 \mu \mathrm{m}, 507 \mu \mathrm{m}$, and $407 \mu \mathrm{m}$, respectively. These further treatments finally resulted in elimination of the subretinal fluid and the overlying exudative RD (OCT retinal thickness at fovea $337 \mu \mathrm{m}$ ), and BCVA improved to 20/40 OS.

A year later, on routine follow-up, the patient presented with recurrence of subretinal fluid diagnosed on OCT and a reduction in BCVA to 20/100 OS. A fifth session of PDT treatment applied and a final OCT 3 months later revealed resolution of subretinal fluid and the choroidal hemangioma (OCT retinal thickness at fovea $300 \mu \mathrm{m}$ ) with a stable final BCVA of 20/100 OS.

\section{Discussion}

This case report exemplifies our experience with Asian patients with diffuse choroidal hemangiomas, who often require multiple treatments with PDT (unpublished). A single

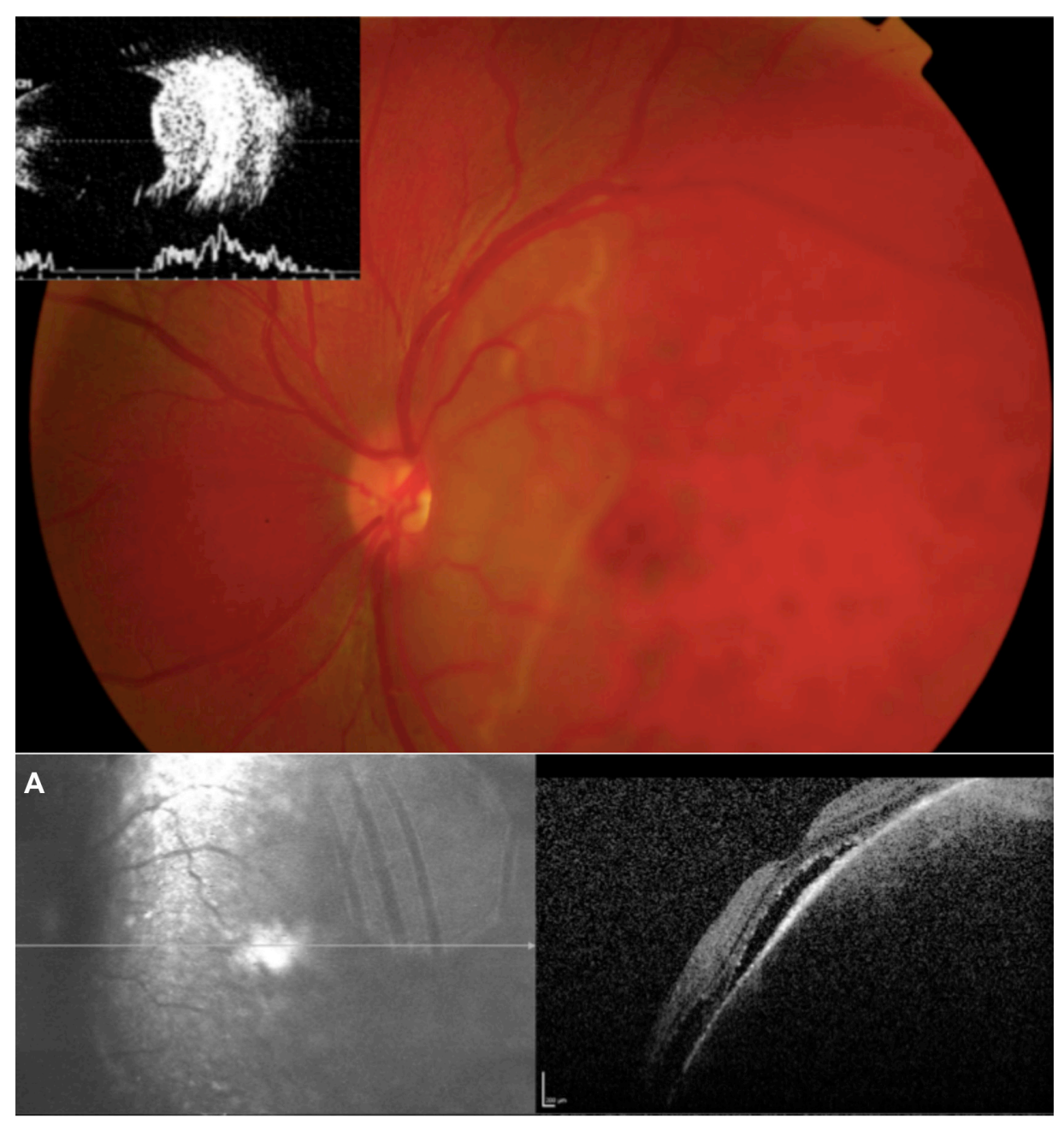

Figure I Fundus photograph showing diffuse, orange choroidal thickening with more prominent localized thickening in the temporal quadrant.

Notes: B-scan ultrasonograph demonstrating a dome-shaped elevated choroidal mass that arises from the diffusely thickened choroid. (A) Optical coherence tomography scans at presentation. 


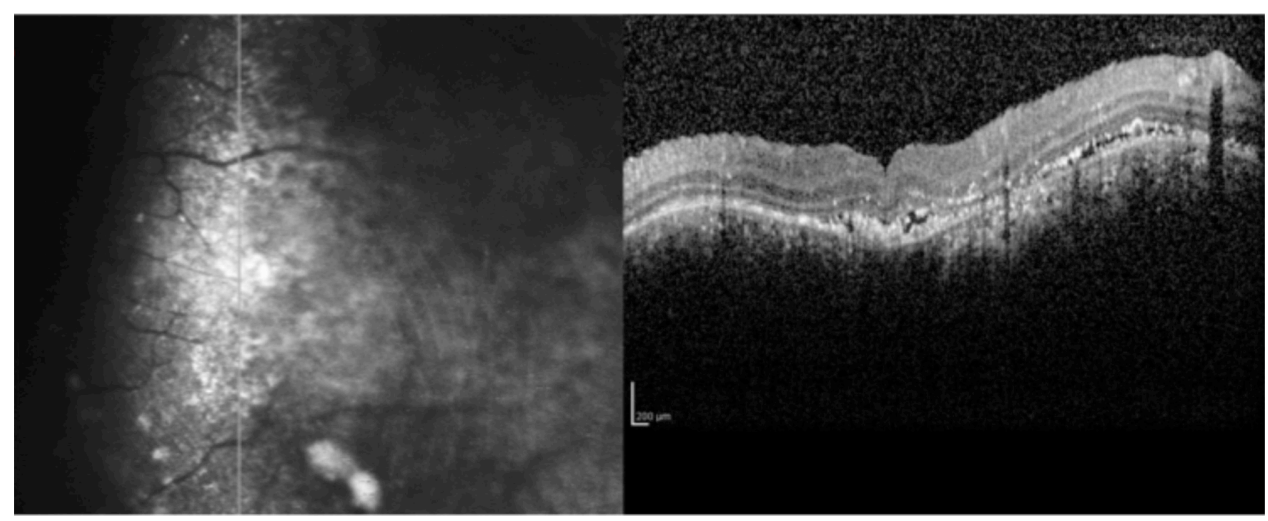

Figure 2 Optical coherence tomography scans after treatment.

application of PDT using currently prescribed parameters is insufficient to destroy the enlarged vessels. This experience is similar to previous reports from China describing circumscribed choroidal hemangiomas. ${ }^{4}$ The decision for repeat treatment was based on subretinal fluid recurrence, rather than on complete tumor regression. However, our patient was refractory to treatment, requiring a total of five PDT sessions.

Factors such as timing of laser application, absorption wavelength, and laser dose characteristics influence the efficacy of PDT. ${ }^{5}$ However, it has been suggested that patients of Asian descent may respond differently to PDT treatment, ${ }^{6}$ possibly due to inherent differences in the retina, such as increased pigmentation in the retinal pigment epithelium. In another study involving Chinese patients, it was suggested that the larger dilated vessels in the vascular network of a choroidal hemangioma might affect the efficacy and selectivity of PDT. ${ }^{4}$

\section{Conclusion}

Diffuse choroidal hemanogiomas associated with SWS are uncommon but require aggressive treatment to prevent visual loss from exudative $\mathrm{RD}$, and possibly, subsequent sequelae such as amblyopia. In Asian patients, diffuse choroidal hemangiomas may require multiple PDT treatment sessions. However, this theory requires further examination with larger studies.

\section{Disclosure}

The authors report no conflicts of interest in this work.

\section{References}

1. Witschel H, Font RL. Hemangioma of the choroid. A clinicopathologic study of 71 cases and a review of the literature. Surv Ophthalmol. 1976;20(6):415-431.

2. Tsipursky MS, Golchet PR, Jampol LM. Photodynamic therapy of choroidal hemangioma in sturge-weber syndrome, with a review of treatments for diffuse and circumscribed choroidal hemangiomas. Surv Ophthalmol. 2011;56(1):68-85.

3. Schmidt-Erfurth UM, Michels S, Kusserow C, Jurklies B, Augustin AJ. Photodynamic therapy for symptomatic choroidal hemangioma: visual and anatomic results. Ophthalmology. 2002;109(12):2284-2294.

4. Zhang Y, Liu W, Fang Y, et al. Photodynamic therapy for symptomatic circumscribed macular choroidal hemangioma in Chinese patients. Am J Ophthalmol. 2010;150(5):710-715. e711.

5. Schmidt-Erfurth U, Hasan T. Mechanisms of action of photodynamic therapy with verteporfin for the treatment of age-related macular degeneration. Surv Ophthalmol. 2000;45(3):195-214.

6. Chan WM, Lai TY, Tano Y, Liu DT, Li KK, Lam DS. Photodynamic therapy in macular diseases of Asian populations: when East meets West. Jpn J Ophthalmol. 2006;50(2):161-169.
Clinical Ophthalmology

\section{Publish your work in this journal}

Clinical Ophthalmology is an international, peer-reviewed journal covering all subspecialties within ophthalmology. Key topics include: Optometry; Visual science; Pharmacology and drug therapy in eye diseases; Basic Sciences; Primary and Secondary eye care; Patient Safety and Quality of Care Improvements. This journal is indexed on

\section{Dovepress}

PubMed Central and CAS, and is the official journal of The Society of Clinical Ophthalmology (SCO). The manuscript management system is completely online and includes a very quick and fair peer-review system, which is all easy to use. Visit http://www.dovepress.com/ testimonials.php to read real quotes from published authors. 